\title{
Effects of Ionic Liquids on Laccase from Trametes versicolor
}

\author{
Aashka Y. Patel ${ }^{1,+}$, Austin K. Clark ${ }^{1,+}$, Nicholas J. Paradis ${ }^{1,+} \mathbb{D}$, Meeraj Amin ${ }^{1}$, Timothy D. Vaden ${ }^{1} \mathbb{D}$, \\ Chun $W u^{1,2}$ and Gregory A. Caputo ${ }^{1,2, *(D)}$
}

1 Department of Chemistry and Biochemistry, Rowan University, Glassboro, NJ 08028, USA; patela87@students.rowan.edu (A.Y.P.); clarka29@students.rowan.edu (A.K.C.); paradi84@students.rowan.edu (N.J.P.); ma1512@scarletmail.rutgers.edu (M.A.); vadent@rowan.edu (T.D.V.); wuc@rowan.edu (C.W.)

2 Department of Molecular and Cellular Biosciences, Rowan University, Glassboro, NJ 08028, USA

* Correspondence: caputo@rowan.edu

$\dagger \quad$ These authors contributed equally.

check for updates

Citation: Patel, A.Y.; Clark, A.K.; Paradis, N.J.; Amin, M.; Vaden, T.D.; Wu, C.; Caputo, G.A. Effects of Ionic Liquids on Laccase from Trametes versicolor. Biophysica 2021, 1, 429-444. https://doi.org/10.3390/

biophysica1040031

Academic Editor: Marc Jamin

Received: 17 September 2021

Accepted: 12 October 2021

Published: 20 October 2021

Publisher's Note: MDPI stays neutral with regard to jurisdictional claims in published maps and institutional affiliations.

Copyright: (C) 2021 by the authors. Licensee MDPI, Basel, Switzerland. This article is an open access article distributed under the terms and conditions of the Creative Commons Attribution (CC BY) license (https:/ / creativecommons.org/licenses/by/ $4.0 /)$.

\begin{abstract}
Interactions between ionic liquids and biomolecules are of great interest due to the intrinsic properties of ionic liquids and the flexibility allowed by mixing and matching cations and anions to create unique ionic liquids. A number of ionic liquid-biomolecule studies have focused on interactions with proteins, including industrially relevant enzymes. One of these, laccase from Trametes versicolor, is a naturally derived enzyme used in the breakdown of phenolic compounds in a wide variety of industries, especially useful in breakdown of lignocellulosic materials. Here, a combination of experiments and molecular dynamics (MD) simulations was used to investigate the interactions of ionic liquids with laccase. Enzyme kinetics assays indicated that ionic liquids composed of tetramethylguanidine (TMG) and either serine or threonine caused significant reduction in enzymatic activity, while kinetics was not impacted by TMG-Asp or TMG-Glu ionic liquids. Similarly, intrinsic fluorescence of laccase in the presence of TMG-Ser and TMG-Thr exhibited a shift in spectral properties consistent with structural destabilization, but again TMG-Asp and TMG-Glu had no impact. MD simulations of laccase and ABTS with/without TMG-Ser ionic liquid provided insight into the deactivation mechanism of laccase. The simulations indicated that TMG-Ser disrupts laccase's electron transfer mechanism.
\end{abstract}

Keywords: ionic liquids; molecular dynamics; laccase; fluorescence

\section{Introduction}

Ionic liquids (ILs) have been an attractive and dynamic topic of investigation in the fields of analytical chemistry and electrochemistry over the past 15-20 years. This interest stems from the many unique and interesting properties of ionic liquids (aka roomtemperature ionic liquids), including low to negligible vapor pressure, high conductivity, non-flammability, and high thermal stability [1]. These properties have made ILs of immediate interest in studies of energy storage and conduction, as well as a variety of other electrochemical applications [2-4]. More recently, groups have begun in-depth investigations into the biocompatibility of ILs as well as the mechanisms of how ILs interact with specific biomolecules.

Proteins, being one of the four major classes of biomolecules, are of obvious interest for investigating IL interactions. The biocompatibility of ILs with proteins is important for developing the scope of applications for a given ionic liquid; that is, ionic liquids which are toxic to cells or destabilize/damage critical proteins cannot be considered for in vivo uses. Alternatively, beneficial chemical properties of ILs may be useful in many industrial bioprocesses in which enzymes are used as biocatalysts for production or conversion applications [5-10]. Specifically, the conductivity of ILs makes them ideal candidates for processes involving redox reactions while the low vapor pressure and thermal stability allow for improved recycling of these agents between processes [9,11-13]. 
The ability for a protein to function in the expected manner is directly linked to the native 3D structure of the protein, and thus maintaining native structure is critical if proteins are to be a useful part of any industrial or experimental process. Protein native structures form through a complex interaction involving H-bonding, hydrophobic forces, ionic interactions, and solvent interactions [14-18]. The protein folding process normally occurs in cells under native cytoplasmic conditions; however, extensive investigation on protein denaturation or unfolding has been carried out in vitro and has yielded significant insights into the thermodynamics of protein structural stability. In the context of ionic liquids, more and more proteins are under investigation for interactions with ionic liquids [19]. This is a challenging problem, as there are seemingly infinite combinations of ionic liquids and proteins to investigate. The interactions of proteins with ILs have been shown to follow the Hofmeister Series, which relates ion identity to effects on protein solubility [20]. Interestingly, some ionic liquids have been shown to stabilize protein structures while others have been demonstrated to destabilize protein structures [21-23]. Thus, there is a critical need to increase the fundamental understanding of how ILs interact with proteins.

A protein widely utilized in industrial bioprocesses is laccase. Laccase was originally isolated from the Japanese lacquer tree Rhus vernicifera, but has since been identified in numerous plant and fungal species [24-29]. Laccases function in nature to oxidize phenolic compounds, utilizing multiple $\mathrm{Cu}^{2+}$ ions at the active site of the protein to facilitate electron transfer. Interestingly, naturally occurring laccases can often catalyze these redox transformations on a number of different substrates. This catalytic promiscuity has enabled laccases to be utilized in the remediation of waste streams from a variety of industries [30]. Laccase has also found widespread utility as a model system when studying the effects of ionic liquids on protein activity. The enzymatic activity of laccase can be monitored through the use of a chromogenic substrate, 2,2'-Azino-bis(3-ethylbenzthiazoline-6-sulfonic acid) (ABTS), which undergoes a color change upon oxidation by laccase. The electron transfer chain has been proposed: electrons that are extracted from phenolic molecules are eventually transferred to dioxygens, forming reduced water and oxidized phenols as end products through an internal pathway involving ABTS, T1 and T2/T3 $\mathrm{Cu}^{2+}$ ions as electron shuttles (Figure 1). This has also allowed a number of groups to investigate the impact of various ionic liquids on the function of laccase $[7,9,31-36]$.

In this study, the impact of two classes of ionic liquids on laccase activity was investigated. The widely studied imidazolium chloride ionic liquids were first investigated, followed by the more recently developed amino-acid based ILs. The imidazolium ILs exhibited variable disruption of laccase enzymatic activity but were incompatible with many spectroscopic studies on proteins due to the high absorptivity of the imidazolium ring in the low-UV region. The amino acid ionic liquids exhibited differential effects on the enzymatic activity of the protein, which was not present when free amino acids were used. Specifically, TMG-Ser and TMG-Thr caused significant reductions in enzymatic activity. (The nomenclature TMG-Ser, TMG-Thr, TMG-Asp, and TMG-Glu will refer to the ionic liquid species added to aqueous solution throughout the manuscript.) Fluorescence spectroscopy confirmed a change in the spectral properties of laccase in the presence of TMG-Ser and TMG-Thr consistent with protein denaturation. MD simulations elucidated the mechanism of inactivation of laccase by TMG-Ser and likely TMG-Thr via disruption of its electron transfer catalysis reaction, likely due to charge-charge (electrostatic) interactions between TMG-ABTS and Ser-T1/T3 $\mathrm{Cu}^{2+}$ ions. 


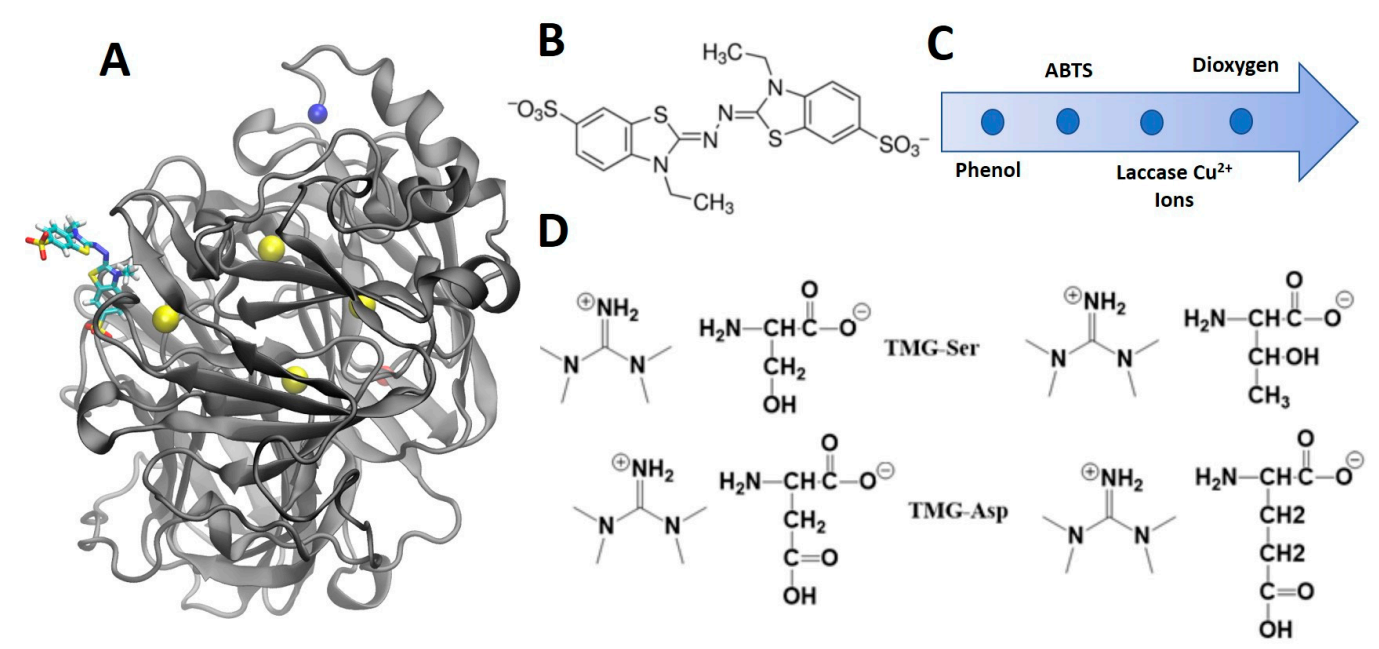

Figure 1. Structure of laccase, ABTS and ionic liquids and the electron transfer chain of the laccase catalysis. (A) Tertiary crystal structure of laccase (PDB ID: 1GYC). Protein backbone: Grey ribbons. ABTS ligand: Licorice tubes colored by element. $\mathrm{Cu}^{2+}$ ions: Yellow VDW balls. N-terminus: Red VDW ball. C-Terminus: Blue VDW ball. T1 $\mathrm{Cu}^{2+}$ ion (left) is adjacent to ABTS; $\mathrm{T}^{2} \mathrm{Cu}^{2+}$ ion (right) is parallel across from $\mathrm{T} 1 \mathrm{Cu}^{2+}$ ion. $\mathrm{T} 3 \mathrm{Cu}^{2+}$ ions (top and bottom) are perpendicular to the $\mathrm{T} 1$ and $\mathrm{T} 2$ $\mathrm{Cu}^{2+}$ ions. (B) Chemical structure of ABTS. (C) The putative electron transporting chain in the redox catalysis mechanism of laccase. Order of electron flow is from left-to-right: an electron is passed from a phenol to ABTS and laccase $\mathrm{Cu}^{2+}$ ions before reducing dioxygen to water. (D) Chemical structures of the ionic liquids TMG-Ser, TMG-Thr, TMG-Asp and TMG-Glu.

\section{Materials and Methods}

\subsection{Materials}

Laccase was purchased as a 70\% pure lyophilized powder from Sigma (St. Louis, MO, USA) and further purified as described below. Imidazolium ionic liquids were purchased from Alfa Aesar (Tewksbury, MA, USA) and used without further purification (99\% purity or greater). All other reagents were purchased from Thermo Fisher Scientific (Waltham, MA, USA), VWR (Radnor, PA, USA), or Sigma-Aldrich (St. Louis, MO, USA). TMG-ILs were synthesized as described previously and contained $\sim 5 \%$ residual water as determined by FTIR spectroscopy [37]. Ionic liquid abbreviations used in the manuscript are: TMG-Ser (1,1,3,3-tetramethylguanidine glutamate), TMG-Thr (1,1,3,3tetramethylguanidine threonine), TMG-Asp (1,1,3,3-tetramethylguanidine aspartate), TMGGlu (1,1,3,3-tetramethylguanidine glutamate), OMICl (1-octyl-3-methylimidazolium chloride,), $\mathrm{HMICl}$ (1-hexyl-3-methylimidazolium chloride,), EMICl (1-ethyl-3-methylimidazolium chloride), and BMICl (1-butyl-3-methylimidazolium chloride).

\subsection{Laccase Purification}

Crude laccase was purified via ion exchange chromatography using a CM sepharose column with ammonium acetate buffer. Crude laccase was dissolved in $50 \mathrm{mM}$ ammonium acetate buffer $\mathrm{pH} 4.1$ and eluted using $50 \mathrm{mM}$ ammonium acetate $\mathrm{pH} 5.1$ buffer. Aliquots of each fraction were removed and checked for laccase activity using ABTS. Active fractions were pooled and dialyzed against $5 \mathrm{mM}$ sodium phosphate $\mathrm{pH}=7.0$ buffer for $\sim 24 \mathrm{~h}$. The sample was then collected and lyophilized. Laccase stock solutions were made fresh by dissolving the lyophilized powder in $2 \mathrm{mM}$ sodium phosphate $\mathrm{pH}=7.0$ and concentration was determined spectrophotometrically using $\varepsilon 280=60,520$.

\subsection{Enzymatic Assay}

Laccase enzyme activity was also measured using absorbance spectroscopy. Briefly, the $5 \mu \mathrm{M}$ purified laccase was mixed with $\mathrm{pH} 5.1$ sodium acetate buffer and added to a quartz cuvette. The solution was stirred within the cuvette using a micro-stir bar. The 
reaction was initiated by the addition of ABTS to a final concentration of $50 \mu \mathrm{M}$ and the increase in absorbance at $450 \mathrm{~nm}$ was monitored as a function of time with auto sampling mode at room temperature. Substrate was added at $t=10 \mathrm{~s}$ in each experiment. Absorbance measurements were collected in $3 \mathrm{~s}$ increments. Data for replicate samples were averaged and standard deviations were calculated and reported as error bars.

\subsection{Fluorescence Spectroscopy}

Fluorescence emission spectra were recorded from laccase using a Horiba Fluoromax 4 fluoresence spectrometer (Horiba Ltd., Edison, NJ, USA). Excitation wavelength was $280 \mathrm{~nm}$ while emissions were collected from 300-400 nm. In these assays, laccase concentration was $6.25 \mu \mathrm{M}$. Ionic liquid concentrations varied based on the experiment. Experiments were carried out in either sodium citrate buffer $\mathrm{pH} 5.1$ or sodium phosphate buffer $\mathrm{pH} 7$. Data presented are representative spectra.

\subsection{Molecular Dynamics Simulations}

MD simulations were performed to probe the deactivation mechanism of laccase enzyme protein in the presence of TMG-Ser. A total of two systems were built: (1.) Laccase and ABTS in water and (2.) Laccase and ABTS with TMG-Ser. The specifics of each system setup are detailed in a supporting document (Table S1). Each system was constructed using the high-resolution structure of laccase (PDB ID: 1GYC) from the RCSB Database (Figure S6). The laccase protein was prepared using the Protein Preparation Wizard of Maestro program [38]. Pre-processing and optimization of the $\mathrm{pH}=7$ protonated state and geometry optimization used default parameters for restricted minimization. The ff14SB force field was used to represent the prepared laccase protein and the disulfide bonds within it. Ions characterizing the ILs were prepared using AMBER16 software and the GAFF2 force field and manually added to the laccase system; the force fields of TMG and Ser molecules were taken from our previous work [37]. Each IL system contained enough ions to constitute $0.05 \mathrm{M}$ concentration. IL molecules were randomly placed around the protein and a relaxation protocol further randomized the IL molecular positions. Each system was built using the TIP3P water solvent model. Each system was contained in a solvent box of truncated octahedron shape using a $10 \AA$ cut-off. Enough counter-ions were added to neutralize each system.

The simulation of each system was carried out using the AMBER 16 simulation package using standard simulation protocols. TMG-Ser IL-containing systems had a 1000 ps pre-run at $500 \mathrm{~K}$ to ensure that the position and orientation of TMG and SER molecules was randomized before a production run at $300 \mathrm{~K}$. Laccase's position remained fixed during this pre-run. A production run at $300 \mathrm{~K}$ included a short $1.0 \mathrm{~ns} \mathrm{MD}$ using the NPT ensemble mode (constant pressure and temperature) to equilibrate the system's density, followed by 999 ns dynamics in the equivalent NVT ensemble mode (constant volume and temperature). All bonds interconnecting hydrogen atoms were treated with the SHAKE algorithm using a $2.0 \mathrm{fs}$ time step in the simulations. Long-range electrostatic interactions were treated with the particle-mesh Ewald method under periodic boundary conditions (charge grid spacing of $\sim 1.0 \AA$, the fourth order of the B-spline charge interpolation, and direct sum tolerance of $10^{-5}$ ) [39]. Short-range non-bonded interactions were defined at $10 \AA$ and long-range van der Waals interactions were based on a uniform density approximation. To reduce computation time and expense, non-bonded forces were calculated using a two-stage RESPA approach [40]. Short-range forces were updated every step and long-range forces were updated every two steps. The temperature was controlled using the Langevin thermostat with a coupling constant of 2.0 ps. The trajectories were saved every 50.0 ps for analysis purposes.

Root mean-squared deviation (RMSD) values were calculated for the laccase protein ( $\mathrm{C} \alpha$ atoms) and ABTS in each system after aligning the $\mathrm{C} \alpha$ atoms of laccase of the first snapshot by least square fitting (Figure S7). Root mean-squared fluctuation (RMSF) values 
were calculated for all individual residues in the laccase protein in water and with TMG-Ser to characterize the entropic change in the protein conformation in each system (Figure S8).

Last, snapshots of laccase and ABTS of each system were generated to quickly assess the structural insights from the MD simulations (Figure S9). In order to account for the stability of the laccase protein backbone in the binding process, the protein backbone of the stable complexes was aligned by a least square fitting. The Daura algorithm was used to cluster all aligned complexes into different structural families based on a $2 \AA$ pair-wise RMSD cutoff of ABTS only, without ligand fit. A centroid structure is defined as a structure with the largest number of neighbors in the structural family and is thus used to represent that structural family. As confirmed via visual analysis, super-families corresponding to major binding modes were formed by merging the centroid structures together (Figure S10). Atom contact plots were generated for Protein-TMG, Protein-Ser, Polar Protein-IL and Nonpolar Protein-IL interactions, with a cut-off of $2.5 \AA$. These plots highlight (1) TMG-protein contacts, (2) Ser-protein contacts, (3) protein polar side chain-IL interactions and (4) protein hydrophobic side chain-IL contacts (Figure S11).

\section{Results}

\subsection{Protein Sequence, Structure and Activity}

Laccase from Trametes versicolor is a 519aa $\mathrm{Cu}^{2+}$-containing protein originally isolated from a white-rot fungus. It normally functions to break down lignins and other plant based materials. The three-dimensional structure of laccase is shown in Figure 1A and a summary of the amino acid sequence and properties can be found in Supplementary Materials Figure S1. The enzymatic activity of the protein was characterized in the presence of either imidazolium ILs EMI-Cl, BMI-Cl, HMI-Cl, OMI-Cl or amino acid ILs TMG-Ser, TMG-Thr, TMG-Asp, TMG-Glu (Figure 1D). The imidazolium ILs vary in the length of the alkyl group attached to the imidazole ring and have been shown to exert differing levels of protein destabilizing activity based on that alkyl chain length $[22,23,41]$. The amino acid ionic liquids are a newer class of ionic liquids and have been demonstrated to exert differential effects on protein stability based on amino acid R-group identity [37]. The amino acid ILs selected represent those with an alcohol in the side chain (Ser, Thr) and those with a carboxyl moiety in the side chain (Asp, Glu).

\subsection{Enzymatic Activity}

The enzymatic activity of laccase in the presence or absence of ILs was characterized by the conversion of the chromogenic substrate ABTS. The ABTS molecule is oxidized by laccase and converted into a cationic radical, which has a different absorbance spectrum than the reduced form. The evolution of this absorbance at $450 \mathrm{~nm}$ is measured as an indicator of laccase activity. In the absence of any ionic liquids, laccase exhibited a typical substrate concentration dependence (Supplementary Materials Figure S2).

\subsubsection{Imidazolium Ionic Liquids}

Laccase activity was measured in the presence of differing concentrations of the four ILs EMI-Cl, BMI-Cl, HMI-Cl, and OMI-Cl. These compounds only differ in the length of the alkyl chain attached to the imidazole ring, ranging from 2 carbons (EMI-Cl) to 8 carbons (OMI-Cl). The data from these experiments are shown in Figure 2. In each case, the laccase activity exhibited a clear dose-dependent decrease in activity as ionic liquids increased. The data shows that even at the lowest ionic liquid concentration tested (0.05 M), there was a noticeable decrease in the conversion ABTS. Importantly, this decrease was more dramatic as the alkyl chain length increased. Similarly, the enzyme activity in the presence of the highest concentration of $\mathrm{OMI}-\mathrm{Cl}$, which contains the longest alkyl chain, was completely abolished (Figure 2D). Interestingly, even the lower concentrations of OMI$\mathrm{Cl}$ induced significant reductions in activity and yielded substrate conversion curves that were atypically shaped. These results may indicate that at lower concentrations OMI-Cl still acts to destabilize the protein but may require longer to achieve the same level of effect. 

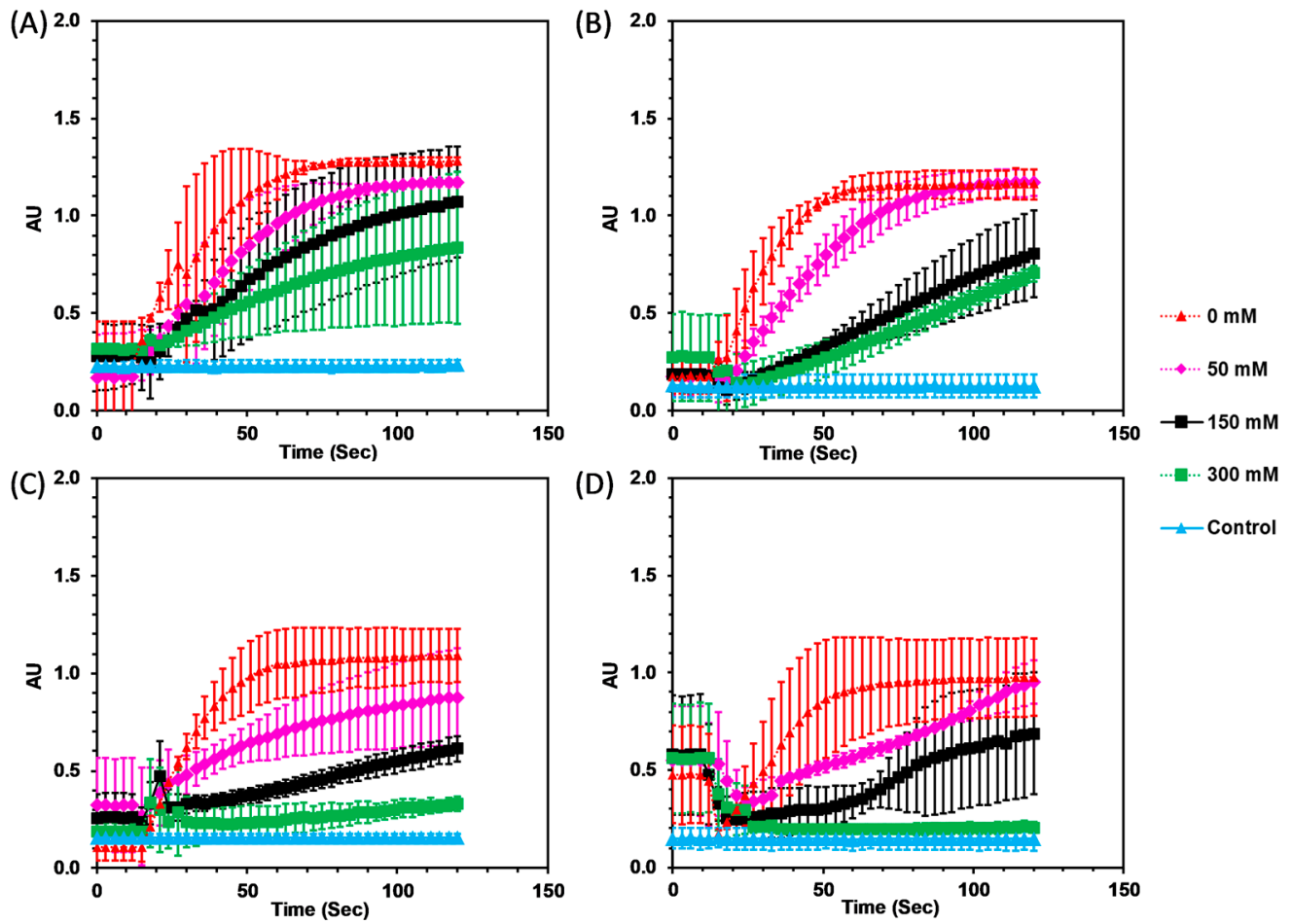

Figure 2. Laccase enzyme activity with imidazolium ILs. The enzymatic conversion of ABTS by laccase is shown in the presence of differing concentrations of (A) EMI-Cl, (B) BMI-Cl, (C) HMI-Cl, or (D) OMI-Cl. Concentrations of IL are shown in the legend, with the "control" sample being laccase and $300 \mathrm{mM}$ IL in the absence of substrate. Substrate was added at $\mathrm{t}=10 \mathrm{~s}$. In all samples, laccase concentration was $5 \mu \mathrm{M}$, ABTS concentration was $50 \mu \mathrm{M}$, and absorbance was monitored at $450 \mathrm{~nm}$. All data are averages of 3-7 samples with error bars representing standard deviations.

\subsubsection{Amino Acid Ionic Liquids}

Unfortunately, there was limited spectroscopic information that could be extracted from the laccase interactions with imidazolium ILs due to the high absorptivity of the imidazole ring in the low-UV region corresponding to wavelengths used in protein circular dichroism and fluorescence spectroscopy. Coupled with the desire to make biocompatible ionic liquids, the focus was shifted to amino acid based ILs. These complexes use a traditional amino acid in complex with another ion to create an ionic liquid. There is increasing interest in these ILs due to the likelihood of tolerance by cellular systems and the existing knowledge of amino acid chemistry and interactions.

Laccase activity was examined in the presence of four different amino acid ILs: TMGSer, TMG-Thr, TMG-Asp, and TMG-Glu (Figure 1D). These amino acid ILs share the TMG cation but vary the associated amino acid, with Asp and Glu being acidic amino acids containing a carboxyl functionality in the side chain and Ser and Thr containing a hydroxyl in the side chain. The laccase activity is shown in Figure 3. In the case of TMG-Ser and TMGThr, there was a complete loss of enzymatic activity under all conditions tested. Conversely, the TMG-Asp and TMG-Glu had effectively no impact on the laccase activity, exhibiting substrate conversion curves nearly indistinguishable from laccase in the absence of ILs. As a control experiment, laccase activity in the presence of free L-Serine was also examined and showed no inhibition of activity (Supplementary Materials Figure S3), indicating that the TMG-Ser ionic liquid behaved differently from either of its subcomponents. 

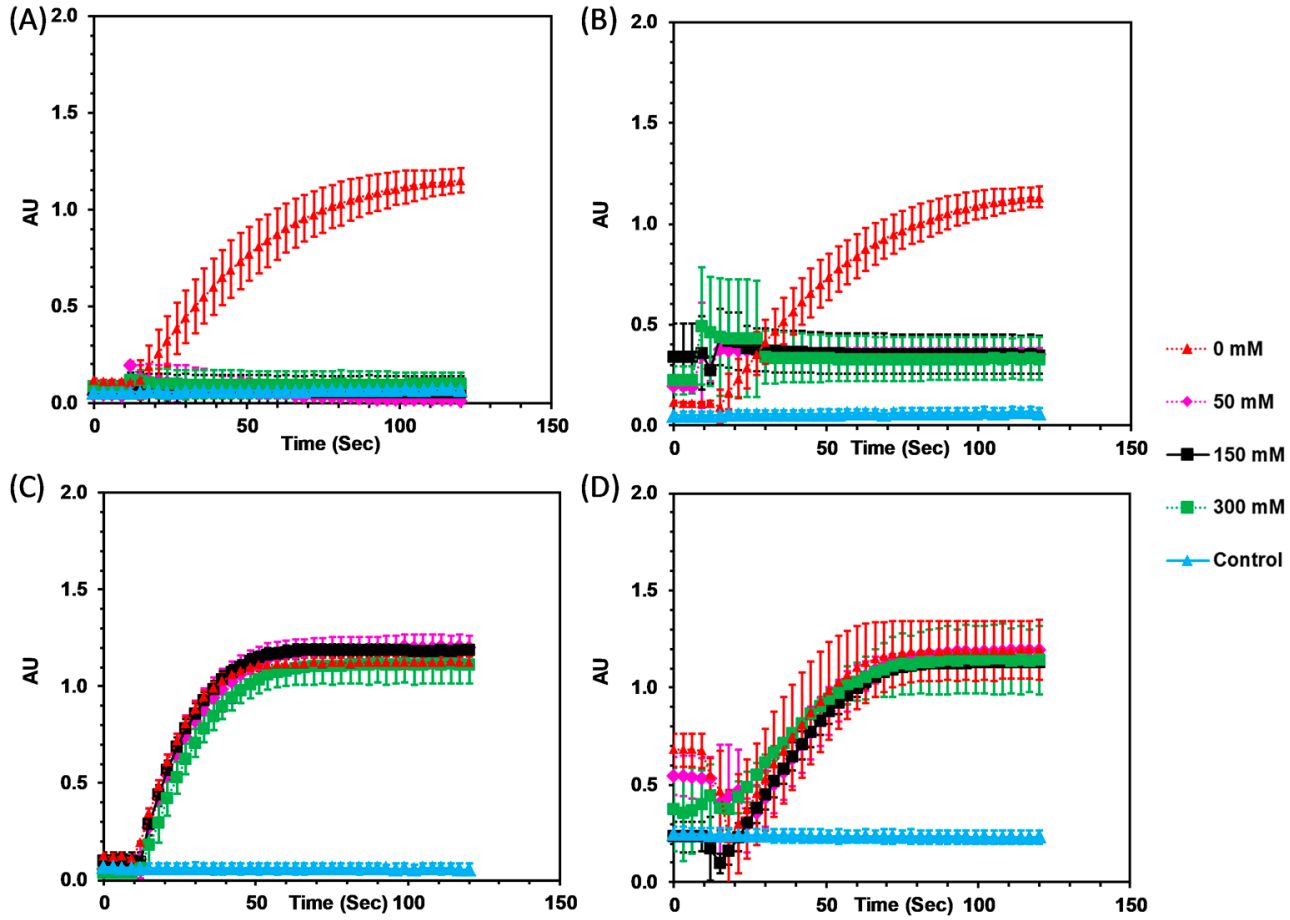

Figure 3. Laccase enzyme activity with amino acid ILs. The enzymatic conversion of ABTS by laccase is shown in the presence of differing concentrations of (A) TMG-Ser, (B) TMG-Thr, (C) TMG-Asp, or (D) TMG-Glu. Concentrations of IL are shown in the legend, with the "control" sample being laccase and $300 \mathrm{mM}$ IL in the absence of substrate. Substrate was added at $\mathrm{t}=10 \mathrm{~s}$. In all samples, laccase concentration was $5 \mu \mathrm{M}$, ABTS concentration was $50 \mu \mathrm{M}$, and absorbance was monitored at $450 \mathrm{~nm}$. All data are averages of 3-7 samples with error bars representing standard deviations.

\subsection{Laccase Intrinsic Fluorescence}

The intrinsic Trp fluorescence of proteins is a useful tool in monitoring protein structure and folding/unfolding processes. The Trp residue is an environmentally sensitive fluorophore which exhibits a dramatic shift in emission wavelength when moving between environments of low polarity and high polarity [42,43]. In the context of protein folding, Trp residues are often located at the interior of folded proteins where the side chain is shielded from the polar aqueous milieu, but as the protein denatures these Trp residues become more exposed to the aqueous environment, resulting in a shift in fluorescence emission spectra [37].

The intrinsic Trp fluorescence from laccase was monitored in the absence and presence of varying concentrations of the amino acid ILs at $\mathrm{pH}$ 5.1, consistent with the conditions used for the enzyme kinetics assays. The emission spectra from these experiments are shown in Figure 4, while additional spectra collected at pH 7 are shown in Supplementary Materials Figure S4. The Trp emission spectra exhibited a concentration-dependent broadening and red shift as the concentration of TMG-Ser or TMG-Thr was increased. The overall shift in the maximum emission wavelength (lmax) and spectral barycenter ranged between 5-10 nm, depending on the conditions. However, the spectra did undergo significant broadening, as evidenced by changes in the ratio of intensities at 330 and $350 \mathrm{~nm}$. The full set of $\lambda \max$, barycenter, and 330/350 ratios can be found in Supplementary Materials Figure S5. In contrast, the spectra of laccase in the presence of TMG-Asp and TMG-Glu exhibited minimal shifting, regardless of IL concentration. Taken together, the fluorescence results are consistent with the observations in enzymatic behavior with the hydroxyl-containing amino acid ILs having significantly greater effect on the protein. The fluorescence results are indicative of protein denaturation or destabilization. 

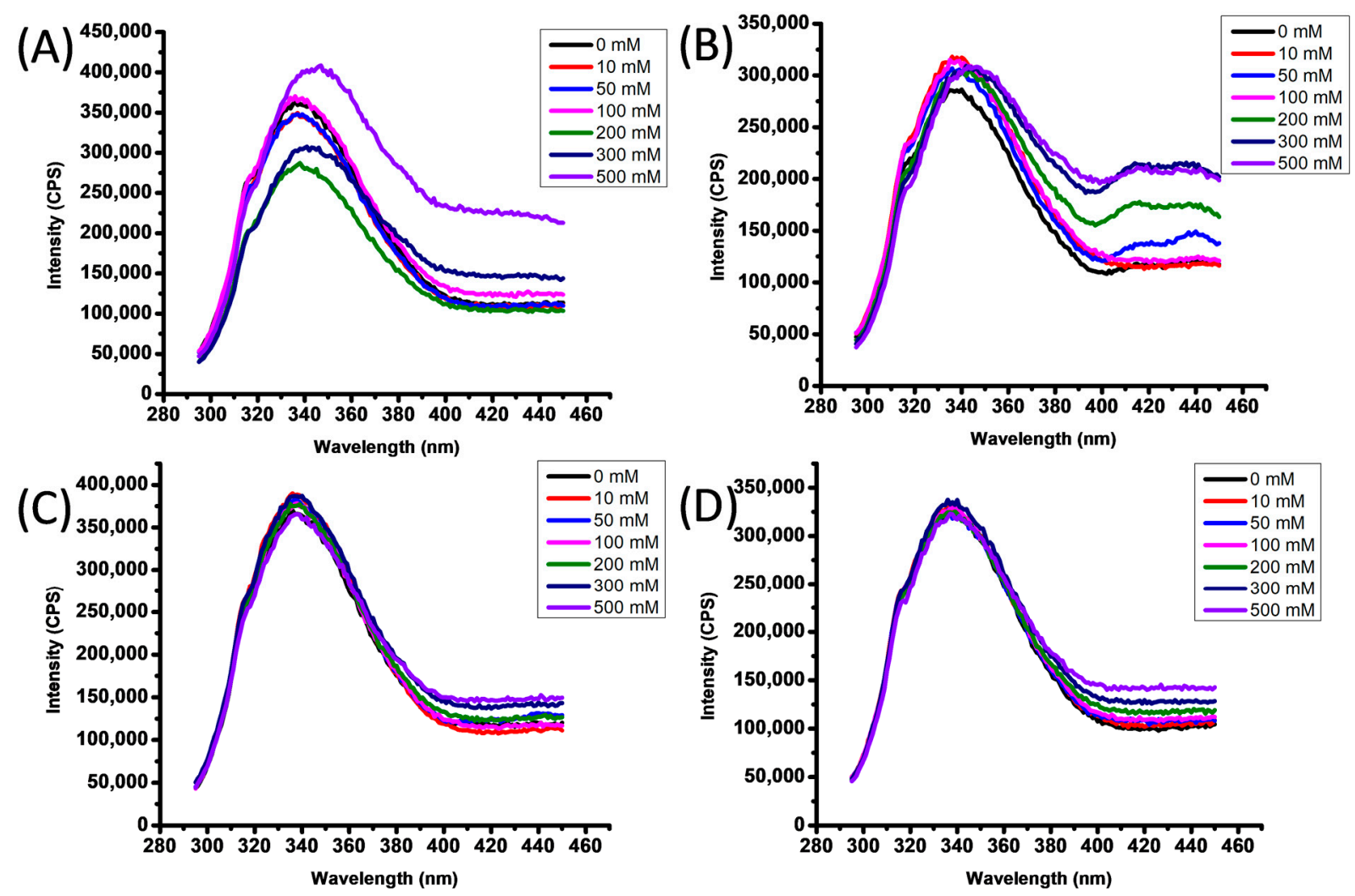

Figure 4. Laccase fluorescence emission spectra at $\mathrm{pH} 5.1$ in the presence and absence of amino acid ionic liquids. In all panels, laccase concentration was $6.25 \mu \mathrm{M}$ and amino acid IL concentrations are denoted in the legend. Fluorescence was measured in the presence of (A) TMG-Ser, (B) TMG-Thr, (C) TMG-Asp, and (D) TMG-Glu. Representative spectra are shown in each panel. Ionic liquid concentrations are shown in the legends.

\subsection{Molecular Dynamics Simulations}

To probe the inhibition mechanism of laccase by TMG-Ser, we simulated laccase with ABTS with and without TMG-Ser. As TMG-Thr has very similar properties to TMG-Ser, we expect our findings from TMG-Ser should be also applicable to TMG-Thr.

To check the convergence of the MD simulations, the average RMSDs over three trajectories for $1000 \mathrm{~ns}$ in water with TMG-Ser are depicted for the C $\alpha$ atoms of the protein receptor and heavy ligand atoms (Figure 5). We observed that laccase underwent a conformational change in the presence of TMG-Ser, but the binding of ABTS to the receptor binding pocket was generally not affected. For reference, RMSD plots for each individual trajectory in water and with TMG-Ser are shown in Supplementary Materials Figure S3. At room temperature, the receptor RMSD was higher in the TMG-Ser system $(\sim 7 \AA)$ than in the water system $(\sim 2 \AA-\sim 3 \AA)$. The ligand RMSD was not significantly different between the two systems $(\sim 7 \AA)$, and thus binding of ABTS to the laccase receptor was not significantly affected. The receptor RMSD converged very early in each system ( $\sim 50 \mathrm{~ns}$ in water and entire trajectory in TMG-Ser), whereas the ligand RMSD converged relatively later ( $\sim 800 \mathrm{~ns}$ in water and $\sim 370 \mathrm{~ns}$ in TMG-Ser). 


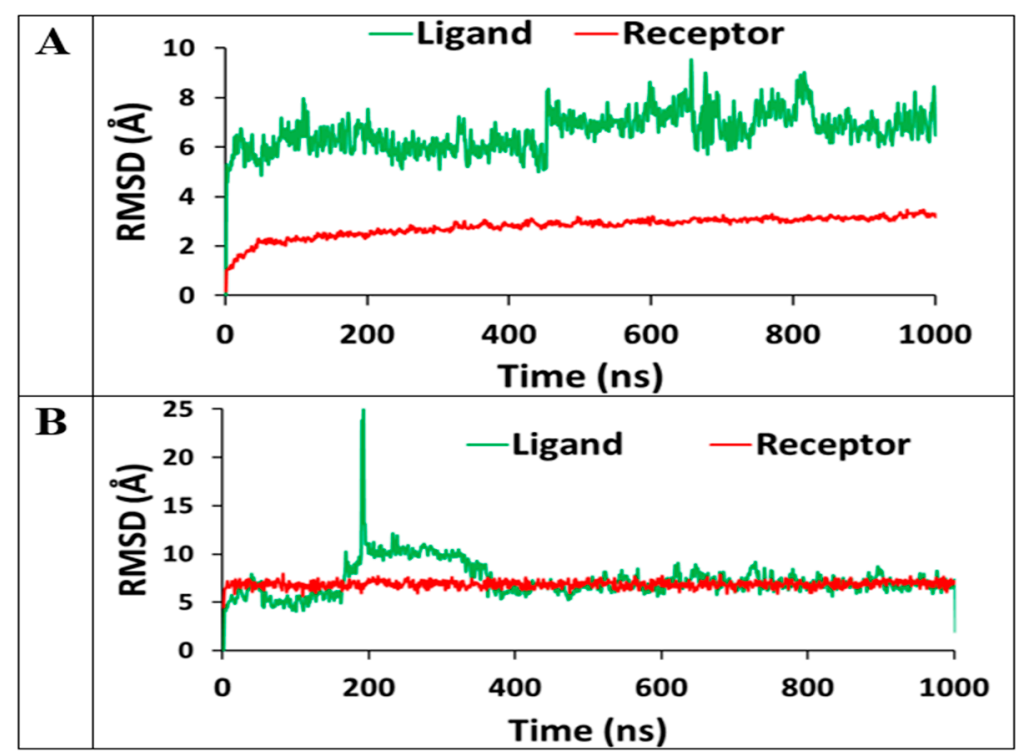

Figure 5. Average RMSD of laccase protein receptor $\mathrm{C} \alpha$ atoms (red) and heavy ligand atoms (green) over three 1000 ns trajectories. (A) In water. (B) In water with TMG-Ser.

RMSF plots for the laccase protein in water and with TMG-Ser over each trajectory were generated (Figure 6 and Figure S8) and the average RMSF values over three trajectories are shown in Figure 6; the average RMSF over all residues was tabulated (Table S3). These data can be used to qualitatively infer the protein conformational entropy. There was virtually no difference in laccase RMSD between the water $(1.8 \pm 0.8)$ and TMG-Ser systems $(1.3 \pm 0.9)$. Throughout most of the protein, the RMSF was relatively low $(<3 \AA)$; however, some spikes existed in the middle of the protein $(\sim 5.8 \AA)$ and at the C-terminus $(\sim 4.5 \AA$ and $10.3 \AA)$. This implies that the flexibility of laccase did not change significantly in the presence of TMG-Ser.

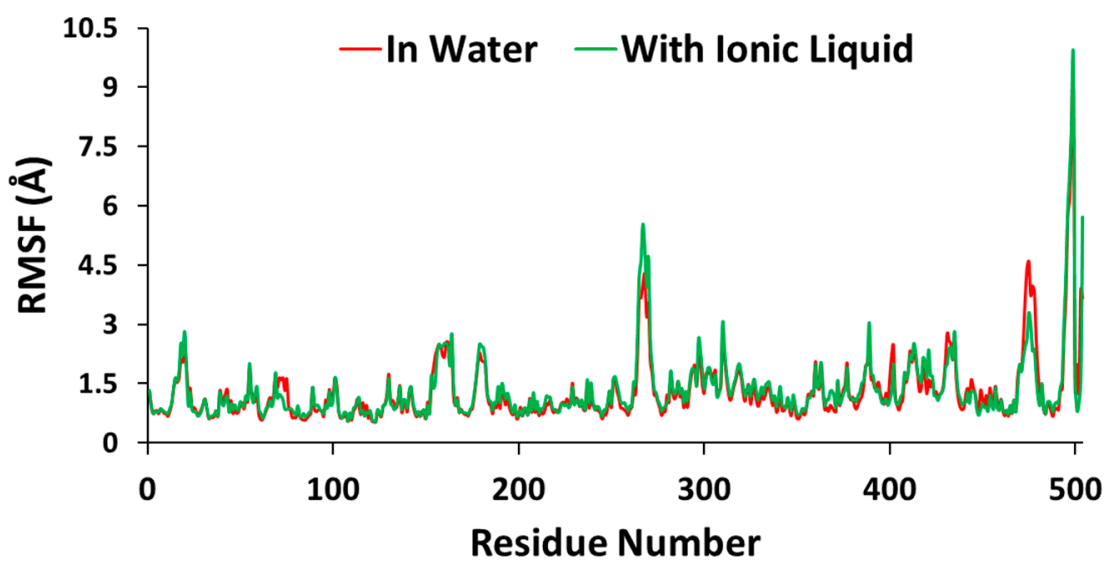

Figure 6. Average RMSF of laccase protein residues (1 to 504) from three $1000 \mathrm{~ns}$ trajectories in water (red) and in water with TMG-Ser (green).

To quickly access the structural insights, we examined the last snapshot of each trajectory from the two systems (Supplementary Materials Figure S9). Between the water and water/TMG-Ser systems, no significant changes were observed in the laccase protein conformation. Additionally, ABTS interaction with the substrate binding pocket occurred in all trajectories except trajectory 2 of the water/TMG-Ser system, where it was pushed slightly out of the binding pocket, thus potentially reducing laccase activity. Interestingly, TMG cations were observed interacting with the solvent-exposed sulfonate group of ABTS as well as laccase. More specifically, Ser anions interacted with the $\mathrm{Cu}^{2+}$ ions buried 
within laccase; trajectories 1 and 3 showed Ser interacting with the same $\mathrm{Cu}^{2+}$ ion, whereas trajectory 2 showed Ser interacting with another $\mathrm{Cu}^{2+}$ ion. These results motivated us to further study the interactions between TMG and Ser with ABTS and laccase $\mathrm{Cu}^{2+}$ ions to elucidate its ability to inactivate laccase.

To probe the effects of TMG-Ser on laccase protein conformation and ABTS ligand binding, clustering analysis was done for the three trajectories of each MD simulation system. Three clusters representing the major conformations of laccase and ABTS with or without TMG-Ser were generated for each system (Supplementary Materials Figure S10). The most abundant clusters of each system were chosen and then superimposed on each other (Figure 7). Based on the RMSD and RMSF results, we expected the global protein and ligand conformations not to change significantly with/without TMG-Ser. Indeed, there were subtle differences in the protein and ligand conformations between the two systems. The protein structure was not destabilized by TMG-Ser; thus, it likely did not contribute to the loss in laccase activity. Interestingly, the binding of ABTS to the laccase substrate binding pocket was not inhibited by TMG-Ser, as its orientation between the two systems was not significantly different. Therefore, a more subtle, local interaction mechanism likely explains the reduction in laccase activity by TMG-Ser.

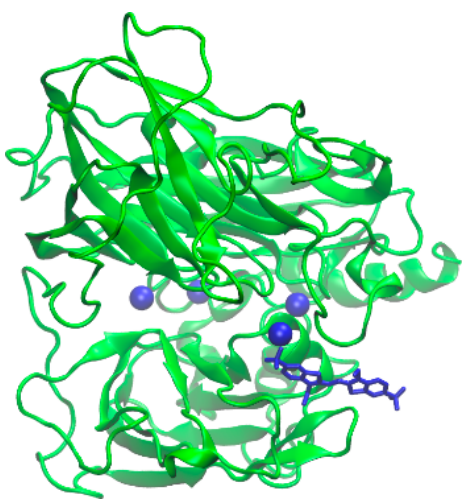

(A)

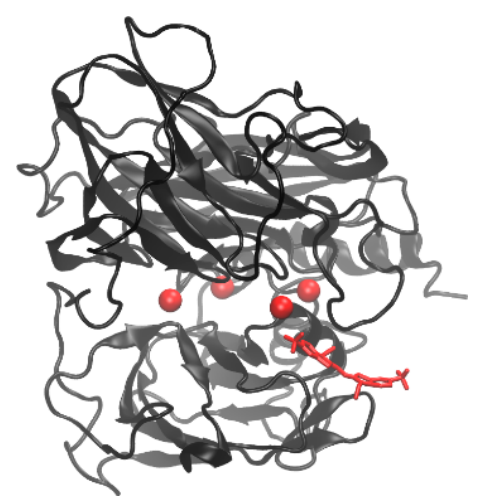

(B)

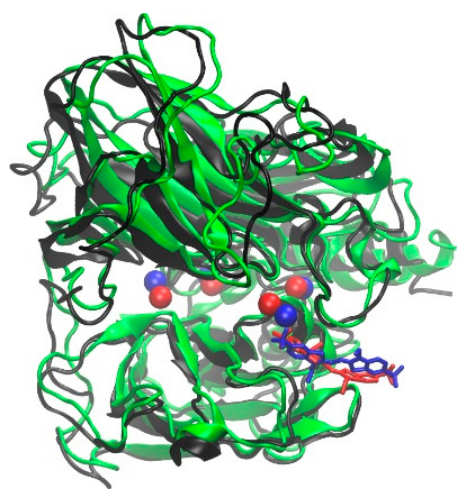

(C)

Figure 7. Superimposition of the most abundant protein and ligand conformations from each system. (A) In water. (B) In TMG-Ser. (C) Cluster (B) Superimposed on Cluster (A).

To probe the interaction mechanism between laccase protein and TMG-Ser IL, we generated an average atom contact plot featuring Protein-TMG, Protein-Ser, Polar ProteinIL and Nonpolar Protein-IL contacts of the three 1000 ns trajectories (Figure 8). Additionally, atom contact plots for each individual trajectory are shown in a supporting document (Supplementary Materials Figure S11). The average number of contacts from the last $200 \mathrm{~ns}$ of Figure 8 have been summarized (Table S2). We observed that the numbers of ProteinTMG and Protein-Ser contacts were not significantly different and that Polar Protein-IL contacts dominated over Nonpolar Protein-IL contacts. Protein-TMG contacts (14 \pm 4$)$ were slightly higher than Protein-Ser contacts (12 \pm 3$)$. This suggests that the nature of the interactions of TMG and Ser with laccase was very similar. Interestingly, there were some points during the trajectory where Protein-TMG and Protein-Ser contacts were relatively consistent ( $\sim 550 \mathrm{~ns}$ to $\sim 700 \mathrm{~ns})$ (Figure $8 \mathrm{~A})$ ). At the end of the trajectory, the number of Protein-TMG contacts spiked moderately ( 25). By comparison, Polar Protein-IL contacts were much more numerous $(22 \pm 2)$ than Nonpolar-IL contacts $(6 \pm 1)$. Unsurprisingly, TMG and Ser are ionic molecules and thus predictably formed greater interactions with polar protein regions. 


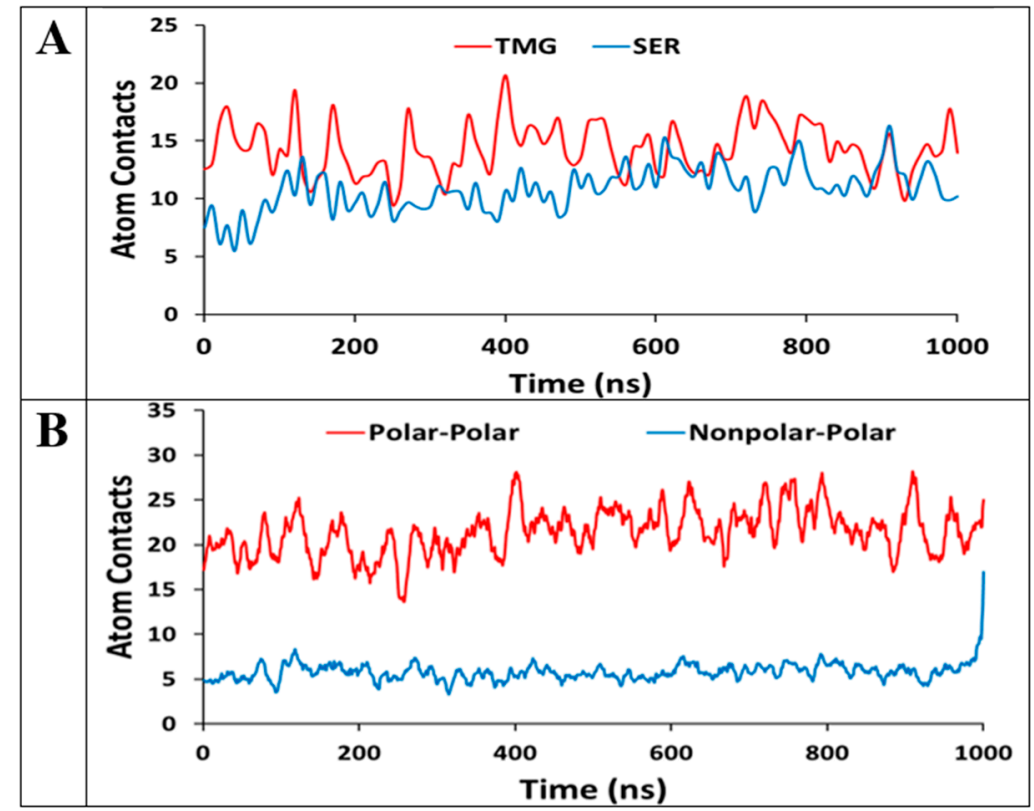

Figure 8. Average atom contacts between laccase protein and TMG-Ser over three 1000 ns trajectories. (A) Interactions of laccase protein with TMG (red) and Ser (blue). (B) Interactions of polar protein (red) and hydrophobic protein (blue) with TMG-Ser.

To obtain detailed interaction between ILs and the protein, we plotted the TMG and SER within $2 \AA$ of $\mathrm{Cu}^{2+}$ ions and ABTS from the combined trajectories (Figure 9). Interestingly, TMG cations clustered around the two sulfonate groups of ABTS, one exposed to the solvent and the other adjacent to the $\mathrm{T} 1 \mathrm{Cu}^{2+}$ ion. The TMG-sulfonate interactions would likely (1.) disrupt electron transfer from a nearby phenol to the solvent-exposed sulfonate group and (2.) disrupt electron transfer from the second sulfonate group to the $\mathrm{T} 1 \mathrm{Cu}^{2+}$ ion. Simultaneously, two dense clusters of Ser anions were located at the T1 and $\mathrm{T} 3 \mathrm{Cu}^{2+}$ ions buried deeper within laccase. The Ser- $\mathrm{Cu}^{2+}$ interactions may disrupt the passing of an electron from $\mathrm{T} 1 \mathrm{Cu}^{2+}$ to its adjacent $\mathrm{T} 3 \mathrm{Cu}^{2+}$. Interestingly, Ser anions were able to move deeper into the $\mathrm{T} 1 \mathrm{Cu}^{2+}$ space than ABTS and thus may act competitively to block ABTS interaction with $\mathrm{T} 1 \mathrm{Cu}^{2+}$. Therefore, TMG-Ser likely disrupts the electron flow mechanism of laccase and thus prevents the reduction of oxygen gas to water.

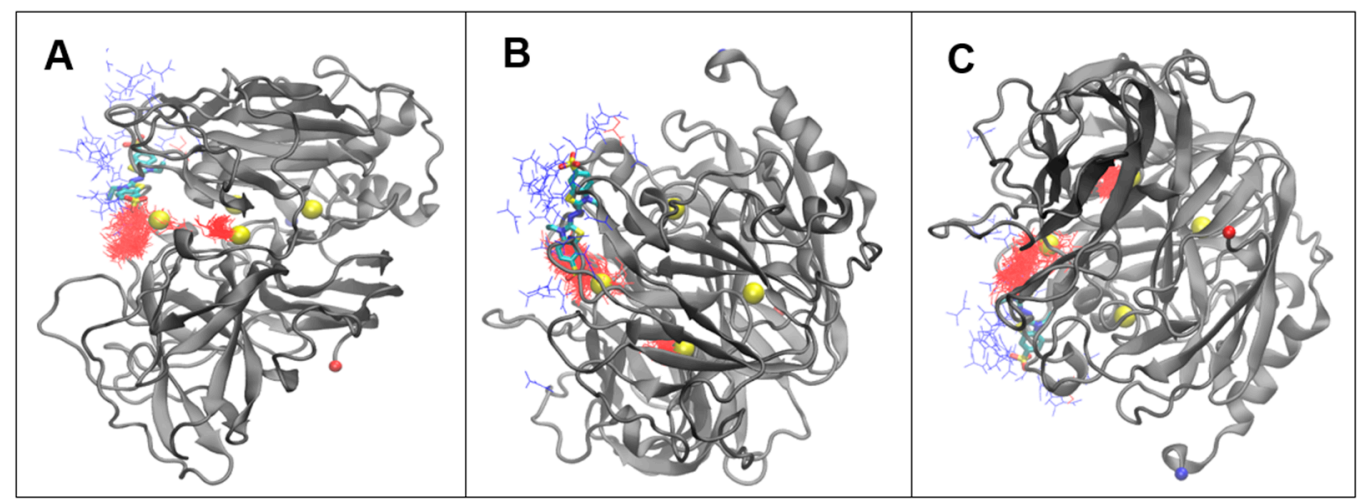

Figure 9. TMG cations and Ser anions within $2 \AA$ of $\mathrm{Cu}^{2+}$ ions and ABTS (VDW) from the trajectories. (A) Side view, (B) Top view; (C): Bottom view; Laccase protein: grey ribbons; $\mathrm{Cu}^{2+}$ ion: yellow ball; SER anion: red line; TMG cation: blue line; N-terminus: red ball; C-terminus: blue ball.

\section{Discussion}

The enzyme laccase has garnered significant interest due to its applicability to industrial processes regarding biomaterials, biowaste, biofuels, and bioremediation $[7,9,10]$. The 
ability to extend the effective working conditions of the enzyme is of interest in order to obtain greater flexibility with regard to substrate preparation and reaction environment. Thus, developing ionic liquids that can maintain enzymatic activity while contributing beneficial solution properties to the samples is the ultimate goal.

The enzymatic activity of laccase is clearly impacted in the presence of some ionic liquids. The imidazolium ILs used as a benchmark as these IL species are relatively well understood regarding protein-IL interactions. The destabilization of protein structure and activity by imidazolium ILs has been correlated to the length of the alkyl chain attached to the imidazole ring $[22,23,31]$. The results using laccase from $T$. versicolor were consistent with the prior findings, in that enzymatic activity was reduced by increasing concentrations of IL, with longer alkyl chain ILs having a more dramatic effect. The shortest chain IL, EMI-Cl, had minimal effect on activity at $50 \mathrm{mM}$ solution concentration and still retained activity at $300 \mathrm{mM}$ concentration. The longest chain, $\mathrm{OMI}-\mathrm{Cl}$, had dramatic effects on activity at all concentrations tested, including complete loss of activity at $300 \mathrm{mM}$ solution concentration. This is consistent with the protein structure being disrupted by the alkyl chains in a detergent-like manner.

The amino acid ILs were shown to disrupt activity according to side chain identity or functional groups. The enzymatic activity of laccase in the presence of TMG-Asp and TMG-Glu was effectively identical to the untreated samples. Conversely, the activity in the presence of TMG-Ser or TMG-Thr was completely eliminated at all concentrations tested. The control experiment showing no loss of activity in the presence of free serine (Supplementary Materials Figure S3), coupled with all amino acid IL species containing the TMG cation, indicated that there was a specific additive or synergistic interaction between TMG and the hydroxyl-containing amino acids in the deactivation of the enzyme.

Elucidating the underlying mechanism of IL-protein interactions can be a significant challenge due to physico-chemical challenges arising from the chemical nature of many ILs. In the case of imidazolium ILs, the inherent absorptivity of the imidazole ring in the low-mid UV region precludes many spectroscopic approaches traditionally used for investigating protein structure, including circular dichroism and intrinsic Trp fluorescence spectroscopy [44,45]. Similarly, the amino acid ILs, due to their composition, prevent the use of any spectroscopic approaches that rely on protein backbone signatures such as circular dichroism or FTIR [46]. Thus, the approaches to investigate given IL-protein systems must be both flexible and robust as some confirmatory approaches will be inaccessible. That said, the case of laccase with amino acid ILs does allow the use of Trp fluorescence spectroscopy, a well-characterized approach to monitoring protein denaturation $[45,47,48]$. The Trp fluorescence emissions spectrum typically exhibits a red-shift due to the side chain becoming more exposed to the polar, aqueous milieu upon protein denaturation. However, this environmental sensitivity can also be influenced by changes in the local environment around the side chain. Gierasch and coworkers were one of the first groups to report abnormally red-shifted Trp fluorescence despite location in a nonpolar environment, which was then confirmed to be a specific Trp-Asp interaction [49,50]. Indeed, according to the MD simulations, laccase does not significantly change 3D structure in the presence of TMG-Ser (see discussion below). Instead, the Trp emission shift appeared to be caused by the binding of Ser near the T3 copper ion. This location is in close proximity to two of the Trp residues in laccase (Trp65 and Trp107). This portion of the protein structure did exhibit some increased flexibility in the simulations with TMG-Ser, as evidenced by small changes in copper ion positions (see below). Thus, it appears that the overall increase in local polarity and the potential interactions between the Trp side chains and the hydroxyl and/or carboxyl groups of Ser caused the emission shift.

From the MD simulations, we observed that laccase protein conformation did not change significantly and ABTS was still able to bind to the laccase catalytic site in the presence of TMG-Ser. Therefore, the change in laccase's global conformation induced by TMG-Ser did not explain its reduced activity. We attributed the inactivation of laccase to localized charge-charge interactions and hydrogen bonding interactions between TMG- 
ABTS and the Ser-T1 $\mathrm{Cu}^{2+}$ ion, and to some degree the Ser-T3 $\mathrm{Cu}^{2+}$ ion, thereby disrupting its electron chain transfer mechanism. It is thus necessary to explain laccase's electron transfer mechanism to understand the combined role of TMG and Ser in disrupting this process. First, a phenolic molecule (i.e., lignin) transfers an electron to a co-oxidizing agent and becomes oxidized (Phenol $\stackrel{e^{-}}{\rightarrow}$ ABTS). Upon binding to laccase's substrate binding pocket, reduced ABTS then transfers its electron to the T1 laccase $\mathrm{Cu}^{2+}$ ion (ABTS $\stackrel{e^{-}}{\rightarrow} \mathrm{T} 1$ $\left.\mathrm{Cu}^{2+}\right)$. $\mathrm{T} 1 \mathrm{Cu}^{2+}$ ion can then transfer its electron to a $\mathrm{T} 3$ or the $\mathrm{T} 2 \mathrm{Cu}^{2+}$ ions $\left(\mathrm{T} 1 \mathrm{Cu}^{2+} \stackrel{e^{-}}{\rightarrow}\right.$ $\left.\mathrm{T} 2 / \mathrm{T} 3 \mathrm{Cu}^{2+}\right)$. T2 and T3 $\mathrm{Cu}^{2+}$ ions contain binding sites for dioxygen, where the final electron transfer occurs to produce water $\left(\mathrm{T} 2 / \mathrm{T} 3 \mathrm{Cu}^{2+} \stackrel{e^{-}}{\rightarrow} \mathrm{O}_{2}\right)$ [51,52]. TMG-Ser likely reduces laccase activity by disrupting its electron transfer mechanism at two critical points: 1.) TMG: Electron transfer from phenols to ABTS and 2.) Ser: Electron transfer from ABTS to the $\mathrm{T} 1 \mathrm{Cu}^{2+}$ ion. Interestingly, under physiological conditions, the sulfonate groups of ABTS, one exposed to the solvent and another close to the $\mathrm{T} 1 \mathrm{Cu}^{2+}$ ion, are deprotonated and become anions. TMG could potentially form a salt-bridge interaction with the solvent-exposed sulfonate and disrupt its ability to accept an electron from a phenol. Simultaneously, Ser could potentially form a hydrogen bond between its hydroxyl side chain and the deprotonated oxygen of the other sulfonate group, disrupting its electron transfer to the $\mathrm{T} 1 \mathrm{Cu}^{2+}$ ion. To some degree, Ser anions also clustered between the $\mathrm{T} 1$ and an adjacent $\mathrm{T} 3 \mathrm{Cu}^{2+}$ ion; again, the hydroxyl group of Ser may disrupt electron transfer between $\mathrm{T} 1$ and $\mathrm{T} 3 \mathrm{Cu}^{2+}$ ions.

Based on the results, TMG-amino acids with hydroxylated side chains seem quite critical for inactivating the redox catalysis reaction of laccase; conversely, TMG-amino acids with carboxylated side chains are relatively ineffective. This might be an issue of the water solubility of each IL. Upon dissociation from TMG, Ser and Thr may likely undergo less interaction with water, allowing them to interact with the T1/T3 $\mathrm{Cu}^{2+}$ ions. On the other hand, Asp and Glu may form too many interactions with water and thus prevent interaction with the $\mathrm{T} 1 / \mathrm{T} 3 \mathrm{Cu}^{2+}$ ions.

The selective inhibition of laccase by TMG-Ser and TMG-Thr could potentially be extended to other biologically-important redox enzymes containing metal cofactors. One example is superoxide dismutase, which utilizes $\mathrm{Cu}^{2+}$ and $\mathrm{Zn}$ metals to convert superoxide radicals to hydrogen peroxide and water [refs]. More importantly, TMG-Ser and TMG-Thr could be used to treat infectious diseases, such as COVID-19. The protein RNA-dependent polymerase (RdRp) contains two $\mathrm{Mg}^{2+}$ ions that catalyze viral replication of SARS-CoV2 [53-55]. The function of this RdRp is dependent on the presence and correct positioning of the $\mathrm{Mg}^{2+}$ ions. Thus, interactions between Ser and Thr with $\mathrm{Mg}^{2+}$ may inactivate RdRp and stop viral replication.

\section{Conclusions}

The combination of experiments and MD simulations of laccase with/without TMGSer elucidated how TMG-Ser causes inactivation of laccase. While fluorescence studies indicated some structural perturbation in the protein, simulations indicated that the TMGSer interactions do not dramatically change the protein structure or the ligand binding conformation. Simulations showed that TMG and Ser both largely interact with polar protein regions. TMG interacts with the sulfonate group of ABTS via ionic interactions while Ser interacts with the $\mathrm{T} 1$ and $\mathrm{T} 3 \mathrm{Cu}^{2+}$ ions via weaker hydrogen bonding interactions, leading to the conclusion that TMG-Ser disrupts the electron transfer mechanism of laccase and thus reduces its activity. Taken together, the combination of simulations and experiments proved to be invaluable in the elucidation of the mechanism for amino acid ILs and, with further experiments and simulations on related systems, could be the basis for developing predictive models for IL-biomolecular interactions.

Supplementary Materials: The following are available online at https:/ / www.mdpi.com/article/10 .3390 / biophysica1040031/s1, Figure S1: Primary structure, secondary structure and topology of $T$. 
versicolor laccase protein (PDB ID: 1GYC) from the PDBsum server, Figure S2: Laccase enzymatic activity with variable substrate concentration. Conversion of ABTS by laccase at $\mathrm{pH} 5.1$ was monitored over time. ABTS concentrations are shown in the legend. Data points are the average of 3-7 replicates and error bars represent standard deviations, Figure S3: Laccase enzymatic activity in the presence of free serine. Conversion of ABTS by laccase at $\mathrm{pH} 5.1$ was monitored over time. ABTS concentrations were constant in all samples. Serine concentrations for each sample are shown in the legend. The control data refers to samples that contained laccase and $300 \mathrm{mM}$ serine but no ABTS. Data points are the average of 3-7 replicates and error bars represent standard deviations, Figure S4: Laccase fluorescence emission spectra at $\mathrm{pH} 7.1$ in the presence and absence of amino acid ionic liquids. In all panels, laccase concentration was $6.25 \mu \mathrm{M}$ and amino acid IL concentrations are denoted in the legend. Fluorescence was measured in the presence of (A) TMG-Ser, (B) TMG-Thr, (C) TMG-Asp, and (D) TMG-Glu. Representative spectra are shown in each panel. Ionic liquid concentrations are shown in the legends, Figure S5: Laccase fluorescence emission spectral properties at pH 5.1 or 7.1 in the presence and absence of amino acid ionic liquids. In all panels, laccase concentration was $6.25 \mathrm{mM}$ and amino acid IL identities are denoted in the legends. Fluorescence properties measured were (A) $\lambda \max$ at $\mathrm{pH} 5.1$, (B) $\lambda$ max at $\mathrm{pH} 7.1$, (C) spectral barycenter at $\mathrm{pH} 5.1$, (D) spectral barycenter at pH 7.1, (E) I350/I330 at pH 5.1, and (F) I350/I330 at pH 7.1, Figure S6: Laccase and ABTS in water (A) and in water with TMG-Ser (B). Protein backbone: Grey ribbons. ABTS ligand: Licorice tubes in yellow. $\mathrm{Cu}^{2+}$ ions: red VDW balls. $\mathrm{T} 1 \mathrm{Cu}^{2+}$ ion (left) is adjacent to ABTS; $22 \mathrm{Cu}^{2+}$ ion (right) is parallel across from $\mathrm{T} 1 \mathrm{Cu}^{2+}$ ion. $\mathrm{T} 3 \mathrm{Cu}^{2+}$ ions (top and bottom) are perpendicular to the $\mathrm{T} 1$ and $\mathrm{T} 2$ $\mathrm{Cu}^{2+}$ ions. TMG: licorice in blue; Ser: licorice in red, Figure S7: RMSD of heavy ligand atoms (green) and laccase protein $\mathrm{C} \alpha$ atoms (red) over three $1000 \mathrm{~ns}$ trajectories. (A) In water. (B) In water with TMG-Ser, Figure S8: RMSF of laccase protein residues (1 to 504) from three 1000 ns trajectories in water (red) and in water with TMG-Ser (green), Figure S9: Last snapshot of three $1000 \mathrm{~ns}$ trajectories of laccase protein with ligand ABTS. (A) In water. (B) In water with TMG-Ser. $\mathrm{Cu}^{2+}$ ion: yellow VDW ball; Ser anion: red VDW ball; TMG cation: blue VDW ball; N-terminus: red VDW ball; C-terminus: blue VDW ball, Figure S10: Most abundant clusters with percentage abundance of three $1000 \mathrm{~ns}$ trajectories of laccase protein with ligand. (A) In water. (B) In water with TMG-Ser, Figure S11: Atom contact plots for laccase protein in TMG-Ser over three $1000 \mathrm{~ns}$ trajectories. (A) Protein in TMG. (B) Protein in Ser. (C) Polar Protein in TMG and Ser. (D) Hydrophobic Protein in TMG and Ser. Red, blue and green lines represent trajectories 1, 2 and 3, respectively, Table S1: Molecular dynamics simulations of Laccase and ABTS with/without IL, Table S2: Average IL-protein contacts for the laccase system containing IL (TMG-Ser), Table S3: Average RMSF values of laccase protein in water and with/without TMG-Ser.

Author Contributions: Conceptualization, G.A.C., T.D.V. and C.W.; methodology, G.A.C., T.D.V. and C.W.; investigation, A.Y.P., A.K.C., N.J.P., M.A.; writing-original draft preparation, G.A.C., T.D.V. and N.J.P.; writing-review and editing, A.Y.P., G.A.C., T.D.V., C.W.; funding acquisition, G.A.C., T.D.V. and C.W. All authors have read and agreed to the published version of the manuscript.

Funding: This research was funded by the National Science Foundation, grant number DMR 1904797. C.W also acknowledges the computer time support from XSEDE MCB 170088 and D. E. Shaw Research on the Anton2 machine allocation (PSCA17017P) hosted by the Pittsburgh Supercomputing Center.

Data Availability Statement: Data is available from the authors upon request.

Acknowledgments: We would like to acknowledge Isabella DeStefano, Gabriella DeStefano, Roshani Patel, and Hunter Gogoj for assistance in synthesizing the ILs.

Conflicts of Interest: The authors declare no conflict of interest.

\section{References}

1. Rogers, R.D.; Seddon, K.R. Ionic Liquids—Solvents of the Future? Science 2003, 302, 792-793. [CrossRef]

2. Martins, V.L.; Torresi, R.M. Ionic liquids in electrochemical energy storage. Curr. Opin. Electrochem. 2018, 9, 26-32. [CrossRef]

3. Liu, H.; Liu, Y.; Li, J. Ionic liquids in surface electrochemistry. Phys. Chem. Chem. Phys. 2010, 12, 1685-1697. [CrossRef] [PubMed]

4. Xue, Z.; Qin, L.; Jiang, J.; Mu, T.; Gao, G. Thermal, electrochemical and radiolytic stabilities of ionic liquids. Phys. Chem. Chem. Phys. 2018, 20, 8382-8402. [CrossRef]

5. Baldrian, P.; Šnajdr, J. Production of ligninolytic enzymes by litter-decomposing fungi and their ability to decolorize synthetic dyes. Enzym. Microb. Technol. 2006, 39, 1023-1029. [CrossRef] 
6. $\mathrm{Xu}, \mathrm{F}$. Oxidation of phenols, anilines, and benzenethiols by fungal laccases: Correlation between activity and redox potentials as well as halide inhibition. Biochemistry 1996, 35, 7608-7614. [CrossRef]

7. Imam, H.T.; Krasňan, V.; Rebroš, M.; Marr, A.C. Applications of Ionic Liquids in Whole-Cell and Isolated Enzyme Biocatalysis. Molecules 2021, 26, 4791. [CrossRef]

8. Itoh, T. Ionic Liquids as Tool to Improve Enzymatic Organic Synthesis. Chem. Rev. 2017, 117, 10567-10607. [CrossRef]

9. Itoh, T.; Takagi, Y. Laccase-Catalyzed Reactions in Ionic Liquids for Green Sustainable Chemistry. ACS Sustain. Chem. Eng. 2021, 9, 1443-1458. [CrossRef]

10. Van Rantwijk, F.; Sheldon, R.A. Biocatalysis in Ionic Liquids. Chem. Rev. 2007, 107, 2757-2785. [CrossRef] [PubMed]

11. Silvester, D.S. Recent advances in the use of ionic liquids for electrochemical sensing. Analyst 2011, 136, 4871-4882. [CrossRef]

12. Watanabe, M.; Thomas, M.L.; Zhang, S.; Ueno, K.; Yasuda, T.; Dokko, K. Application of ionic liquids to energy storage and conversion materials and devices. Chem. Rev. 2017, 117, 7190-7239. [CrossRef]

13. Zhao, H.; Malhotra, S.V. Applications of ionic liquids in organic synthesis. Aldrichimica Acta 2002, 35, 75-83. [CrossRef]

14. Baker, D. What has de novo protein design taught us about protein folding and biophysics? Protein Sci. 2019, $28,678-683$. [CrossRef]

15. Dobson, C.M. Protein folding and misfolding. Nature 2003, 426, 884-890. [CrossRef]

16. Dobson, C.M.; Šali, A.; Karplus, M. Protein folding: A perspective from theory and experiment. Angew. Chem. Int. Ed. 1998, 37, 868-893. [CrossRef]

17. England, J.L.; Haran, G. Role of solvation effects in protein denaturation: From thermodynamics to single molecules and back. Annu. Rev. Phys. Chem. 2011, 62, 257-277. [CrossRef] [PubMed]

18. Sorokina, I.; Mushegian, A. Modeling protein folding in vivo. Biol. Direct 2018, 13, 13. [CrossRef] [PubMed]

19. Patel, A.Y.; Jonnalagadda, K.S.; Paradis, N.; Vaden, T.D.; Wu, C.; Caputo, G.A. Effects of Ionic Liquids on Metalloproteins. Molecules 2021, 26, 514. [CrossRef]

20. Zhao, H. Are ionic liquids kosmotropic or chaotropic? An evaluation of available thermodynamic parameters for quantifying the ion kosmotropicity of ionic liquids. J. Chem. Technol. Biotechnol. Int. Res. Process. Environ. Clean Technol. 2006, 81, 877-891.

21. Weingärtner, H.; Cabrele, C.; Herrmann, C. How ionic liquids can help to stabilize native proteins. Phys. Chem. Chem. Phys. 2012, 14, 415-426. [CrossRef]

22. Fiebig, O.C.; Mancini, E.; Caputo, G.; Vaden, T.D. Quantitative Evaluation of Myoglobin Unfolding in the Presence of Guanidinium Hydrochloride and Ionic Liquids in Solution. J. Phys. Chem. B 2014, 118, 406-412. [CrossRef]

23. Lee, J.Y.; Selfridge, K.M.; Kohn, E.M.; Vaden, T.D.; Caputo, G.A. Effects of Ionic Liquid Alkyl Chain Length on Denaturation of Myoglobin by Anionic, Cationic, and Zwitterionic Detergents. Biomolecules 2019, 9, 264. [CrossRef] [PubMed]

24. Bao, W.; O'Malley, D.M.; Whetten, R.; Sederoff, R.R. A laccase associated with lignification in loblolly pine xylem. Science 1993, 260, 672-674. [CrossRef] [PubMed]

25. Kiefer-Meyer, M.-C.; Gomord, V.; O'Connell, A.; Halpin, C.; Faye, L. Cloning and sequence analysis of laccase-encoding cDNA clones from tobacco. Gene 1996, 178, 205-207. [CrossRef]

26. LaFayette, P.R.; Eriksson, K.-E.L.; Dean, J.F. Characterization and heterologous expression of laccase cDNAs from xylem tissues of yellow-poplar (Liriodendron tulipifera). Plant Mol. Biol. 1999, 40, 23-35. [CrossRef]

27. Ranocha, P.; McDougall, G.; Hawkins, S.; Sterjiades, R.; Borderies, G.; Stewart, D.; Cabanes-Macheteau, M.; Boudet, A.M.; Goffner, D. Biochemical characterization, molecular cloning and expression of laccases-a divergent gene family-in poplar. Eur. J. Biochem. 1999, 259, 485-495. [CrossRef] [PubMed]

28. Sato, Y.; Wuli, B.; Sederoff, R.; Whetten, R. Molecular cloning and expression of eight laccase cDNAs in loblolly pine (Pinus taeda). J. Plant Res. 2001, 114, 147-155. [CrossRef]

29. Sterjiades, R.; Dean, J.F.; Eriksson, K.-E.L. Laccase from sycamore maple (Acer pseudoplatanus) polymerizes monolignols. Plant Physiol. 1992, 99, 1162-1168. [CrossRef]

30. Couto, S.R.; Herrera, J.L.T. Industrial and biotechnological applications of laccases: A review. Biotechnol. Adv. 2006, 24, 500-513. [CrossRef]

31. Dabirmanesh, B.; Khajeh, K.; Ghazi, F.; Ranjbar, B.; Etezad, S.-M. A semi-rational approach to obtain an ionic liquid tolerant bacterial laccase through $\pi$-type interactions. Int. J. Biol. Macromol. 2015, 79, 822-829. [CrossRef]

32. Jolivalt, C.; Madzak, C.; Brault, A.; Caminade, E.; Malosse, C.; Mougin, C. Expression of laccase IIIb from the white-rot fungus Trametes versicolor in the yeast Yarrowia lipolytica for environmental applications. Appl. Microbiol. Biotechnol. 2005, 66, 450-456. [CrossRef]

33. Saoudi, O.; Ghaouar, N.; Othman, T. Fluorescence study of laccase from Trametes versicolor under the effects of $\mathrm{pH}$, chemical denaturants and ionic liquids. J. Mol. Liq. 2017, 225, 56-63. [CrossRef]

34. Tavares, A.P.M.; Pereira, J.A.N.; Xavier, A.M.R.B. Effect of ionic liquids activation on laccase from Trametes versicolor: Enzymatic stability and activity. Eng. Life Sci. 2012, 12, 648-655. [CrossRef]

35. Tavares, A.P.M.; Rodriguez, O.; Macedo, E.A. Ionic liquids as alternative co-solvents for laccase: Study of enzyme activity and stability. Biotechnol. Bioeng. 2008, 101, 201-207. [CrossRef] [PubMed]

36. Zhao, H. Effect of ions and other compatible solutes on enzyme activity, and its implication for biocatalysis using ionic liquids. J. Mol. Catal. B Enzym. 2005, 37, 16-25. [CrossRef] 
37. DeStefano, I.; DeStefano, G.; Paradis, N.J.; Patel, R.; Clark, A.K.; Gogoj, H.; Singh, G.; Jonnalagadda, K.S.; Patel, A.Y.; Wu, C.; et al. Thermodynamic destabilization of azurin by four different tetramethylguanidinium amino acid ionic liquids. Int. J. Biol. Macromol. 2021, 180, 355-364. [CrossRef] [PubMed]

38. Madhavi Sastry, G.; Adzhigirey, M.; Day, T.; Annabhimoju, R.; Sherman, W. Protein and ligand preparation: Parameters, protocols, and influence on virtual screening enrichments. J. Comput. Aided Mol. Des. 2013, 27, 221-234. [CrossRef]

39. Essmann, U.; Perera, L.; Berkowitz, M.L.; Darden, T.; Lee, H.; Pedersen, L.G. A smooth particle mesh Ewald method. J. Chem. Phys. 1995, 103, 8577-8593. [CrossRef]

40. Procacci, P.; Berne, B.J. Multiple time scale methods for constant pressure molecular dynamics simulations of molecular systems. Mol. Phys. 1994, 83, 255-272. [CrossRef]

41. Kohn, E.M.; Lee, J.Y.; Calabro, A.; Vaden, T.D.; Caputo, G.A. Heme Dissociation from Myoglobin in the Presence of the Zwitterionic Detergent N,N-Dimethyl-N-Dodecylglycine Betaine: Effects of Ionic Liquids. Biomolecules 2018, 8, 126. [CrossRef] [PubMed]

42. Chen, Y.; Barkley, M.D. Toward Understanding Tryptophan Fluorescence in Proteins. Biochemistry 1998, 37, 9976-9982. [CrossRef] [PubMed]

43. Vivian, J.T.; Callis, P.R. Mechanisms of Tryptophan Fluorescence Shifts in Proteins. Biophys. J. 2001, 80, 2093-2109. [CrossRef]

44. Kelly, S.M.; Price, N.C. The use of circular dichroism in the investigation of protein structure and function. Curr. Protein Pept. Sci. 2000, 1, 349-384. [CrossRef]

45. Eftink, M.R. The use of fluorescence methods to monitor unfolding transitions in proteins. Biophys. J. 1994, 66, 482-501. [CrossRef]

46. Acharyya, A.; DiGiuseppi, D.; Stinger, B.L.; Schweitzer-Stenner, R.; Vaden, T.D. Structural Destabilization of Azurin by Imidazolium Chloride Ionic Liquids in Aqueous Solution. J. Phys. Chem. B 2019, 123, 6933-6945. [CrossRef]

47. Zhong, D.; Pal, S.K.; Zhang, D.; Chan, S.I.; Zewail, A.H. Femtosecond dynamics of rubredoxin: Tryptophan solvation and resonance energy transfer in the protein. Proc. Natl. Acad. Sci. USA 2002, 99, 13. [CrossRef]

48. Ghirlanda, G.; Lear, J.D.; Ogihara, N.L.; Eisenberg, D.; DeGrado, W.F. A Hierarchic Approach to the Design of Hexameric Helical Barrels. J. Mol. Biol. 2002, 319, 243-253. [CrossRef]

49. Jones, J.D.; Gierasch, L.M. Effect of charged residue substitutions on the membrane-interactive properties of signal sequences of the Escherichia coli LamB protein. Biophys. J. 1994, 67, 1534-1545. [CrossRef]

50. Caputo, G.A.; London, E. Position and ionization state of Asp in the core of membrane-inserted alpha helices control both the equilibrium between transmembrane and nontransmembrane helix topography and transmembrane helix positioning. Biochemistry 2004, 43, 8794-8806. [CrossRef]

51. Enguita, F.J.; Marçal, D.; Martins, L.O.; Grenha, R.; Henriques, A.O.; Lindley, P.F.; Carrondo, M.A. Substrate and Dioxygen Binding to the Endospore Coat Laccase from Bacillus subtilis*. J. Biol. Chem. 2004, 279, 23472-23476. [CrossRef]

52. Ferraroni, M.; Myasoedova, N.M.; Schmatchenko, V.; Leontievsky, A.A.; Golovleva, L.A.; Scozzafava, A.; Briganti, F. Crystal structure of a blue laccase from Lentinus tigrinus: Evidences for intermediates in the molecular oxygen reductive splitting by multicopper oxidases. BMC Struct. Biol. 2007, 7, 60. [CrossRef] [PubMed]

53. Yasui, K.; Baba, A. Therapeutic potential of superoxide dismutase (SOD) for resolution of inflammation. Inflamm. Res. 2006, 55, 359-363. [CrossRef] [PubMed]

54. Picarazzi, F.; Vicenti, I.; Saladini, F.; Zazzi, M.; Mori, M. Targeting the RdRp of Emerging RNA Viruses: The Structure-Based Drug Design Challenge. Molecules 2020, 25, 5695. [CrossRef] [PubMed]

55. Tainer, J.A.; Getzoff, E.D.; Richardson, J.S.; Richardson, D.C. Structure and mechanism of copper, zinc superoxide dismutase. Nature 1983, 306, 284-287. [CrossRef] 